\title{
Efficacy of Hair Total Mercury Content as a Biomarker of Methylmercury Exposure to Communities in the Area of Artisanal and Small-Scale Gold Mining in Madre de Dios, Peru
}

\author{
Faye Koenigsmark ${ }^{1}\left(\mathbb{D}\right.$, Caren Weinhouse ${ }^{2}$, Axel J. Berky ${ }^{3}$, Ana Maria Morales ${ }^{4}$, Ernesto J. Ortiz ${ }^{5}{ }^{\circledR}$, \\ Eric M. Pierce ${ }^{6}$, William K. Pan ${ }^{3,7, *(1)}$ and Heileen Hsu-Kim ${ }^{1, *(1)}$
}

check for updates

Citation: Koenigsmark, F.;

Weinhouse, C.; Berky, A.J.; Morales, A.M.; Ortiz, E.J.; Pierce, E.M.; Pan, W.K.; Hsu-Kim, H. Efficacy of Hair Total Mercury Content as a Biomarker of Methylmercury Exposure to Communities in the Area of Artisanal and Small-Scale Gold Mining in Madre de Dios, Peru. Int. J. Environ. Res. Public Health 2021, 18, 13350. https://doi.org/10.3390/ijerph 182413350

Academic Editor: Paul B. Tchounwou

Received: 3 November 2021

Accepted: 8 December 2021

Published: 18 December 2021

Publisher's Note: MDPI stays neutral with regard to jurisdictional claims in published maps and institutional affiliations.

Copyright: (C) 2021 by the authors Licensee MDPI, Basel, Switzerland. This article is an open access article distributed under the terms and conditions of the Creative Commons Attribution (CC BY) license (https:// creativecommons.org/licenses/by/ $4.0 /)$.
1 Civil and Environmental Engineering, Duke University, Durham, NC 27708, USA; faye.koenigsmark@duke.edu

2 Oregon Institute of Occupational Health Sciences, Oregon Health \& Science University, 3181 SW Sam Jackson Park Road, Portland, OR 97239, USA; weinhous@ohsu.edu

3 Nicholas School of the Environment, Duke University, 9 Circuit Drive, Durham, NC 27710, USA; axel.berky@duke.edu

4 Centro Nacional de Salud Intercultural, Instituto Nacional de Salud, Ministerio de Salud, Cápac Yupanqui 1400-Jesus María, Lima 15027, Peru; anamorales30@hotmail.com

5 Duke Global Health Innovation Center, Duke University, 310 Blackwell Street, Durham, NC 27701, USA; ernesto.ortiz@duke.edu

6 Environmental Sciences Division, Oak Ridge National Laboratory, 1 Bethel Valley, Oak Ridge, TN 37831, USA; pierceem@ornl.gov

7 Duke Global Health Institute, Duke University, 310 Trent Drive, Durham, NC 27710, USA

* Correspondence: william.pan@duke.edu (W.K.P.); hsukim@duke.edu (H.H.-K.); Tel.: +1-(919)-660-5109 (H.H.-K.)

Abstract: Total mercury content (THg) in hair is an accepted biomarker for chronic dietary methylmercury (MeHg) exposure. In artisanal and small-scale gold mining (ASGM) communities, the validity of this biomarker is questioned because of the potential for contamination from inorganic mercury. As mining communities may have both inorganic and organic mercury exposures, the efficacy of the hair-THg biomarker needs to be evaluated, particularly as nations begin population exposure assessments under their commitments to the Minamata Convention. We sought to validate the efficacy of hair $\mathrm{THg}$ for public health monitoring of $\mathrm{MeHg}$ exposures for populations living in ASGM communities. We quantified both $\mathrm{THg}$ and $\mathrm{MeHg}$ contents in hair from a representative subset of participants $(\mathrm{N}=287)$ in a large, population-level mercury exposure assessment in the ASGM region in Madre de Dios (MDD), Peru. We compared population $\mathrm{MeHg}-\mathrm{THg}$ correlations and \% $\mathrm{MeHg}$ values with demographic variables including community location, sex, occupation, and nativity. We observed that hair MeHg-THg correlations were high ( $r>0.7)$ for all communities, regardless of location or nativity. Specifically, for individuals within ASGM communities, 81\% (121 of 150 total) had hair $\mathrm{THg}$ predominantly in the form of $\mathrm{MeHg}$ (i.e., $>66 \%$ of $\mathrm{THg}$ ) and reflective of dietary exposure to mercury. Furthermore, for individuals with hair THg exceeding the U.S. EPA threshold $(1.0 \mu \mathrm{g} / \mathrm{g}), 88$ out of $106(83 \%)$ had MeHg as the predominant form. As a result, had urine THg solely been used for mercury exposure monitoring, approximately $59 \%$ of the ASGM population would have been misclassified as having low mercury exposure. Our results support the use of hair $\mathrm{THg}$ for monitoring of $\mathrm{MeHg}$ exposure of populations in ASGM settings where alternative biomarkers of $\mathrm{MeHg}$ exposure are not feasible.

Keywords: mercury; exposure biomarker; population monitoring; mining

\section{Introduction}

The Minamata Convention on Mercury is an international effort to reduce the negative impacts of anthropogenic mercury pollution. As part of global advancements towards 
this goal, signatory nations are establishing regional biomonitoring programs for mercury exposures. For populations near artisanal and small-scale gold mining (ASGM), biomonitoring for $\mathrm{Hg}$ exposure is a special challenge because individuals within these populations can be exposed to multiple forms of mercury, requiring different strategies for detection.

ASGM is a largely unregulated mining technique responsible for over $30 \%$ of anthropogenic mercury $(\mathrm{Hg})$ emissions to the atmosphere [1], and involves the use of liquid elemental mercury $\left(\mathrm{Hg}^{0} \mathrm{~L}\right)$ to amalgamate and separate gold from excavated soils [2]. The gold is refined by heating the amalgam and evaporating the mercury, a process occurring both at excavation sites as well as in gold shops at local population centers.

Individuals engaged in smelting and amalgamation activities in ASGM are exposed to inorganic $\mathrm{Hg}$ forms (e.g., $\mathrm{Hg}^{0} \mathrm{~L}$ vapors), which can be monitored through the analysis of urine biomarkers [3,4]. However, in mining areas where aquatic wildlife is an important protein source, such as ASGM regions throughout South America [5-7], Africa [8,9], and South Asia [10,11], methylmercury $(\mathrm{MeHg})$ exposure is also a concern [5,12], particularly for children who are at risk for neurological impairment [13,14].

Chronic MeHg exposure cannot be evaluated by urine biomarkers [4]; rather this type of exposure is often evaluated by quantifying total mercury $(\mathrm{THg})$ content in hair, a wellestablished biomarker of $\mathrm{MeHg}$ burden in the brain-its primary target tissue [15,16]. This biomarker relies on the assumption that the majority of $\mathrm{THg}$ in the matrix is $\mathrm{MeHg}$, and with hair growth rate of approximate $1 \mathrm{~cm}$ per month, the biomarker represents multiple months of exposure, depending of the hair length analyzed [13,17-19]. For regions that host ASGM activity, however, the THg hair biomarker for population monitoring of $\mathrm{MeHg}$ exposure has not been recommended in the draft effectiveness evaluation of the Minamata Convention [4,20], due to questions raised in recent reports [13,21-23]. These doubts are based on studies of individuals engaged in ASGM activity showing that the percentage of hair THg as $\mathrm{MeHg}$ ranged from $1 \%$ to $110 \%$ (Supplemental Information Table S1) [22,24-29]. In contrast, control groups consisting of individuals from areas with no known ASGM activity had average hair \%MeHg values of $84 \% \pm 18 \%$ (Supplemental Information Table S2) [22,30-37]. Inorganic mercury $(\mathrm{iHg})$ can accumulate in hair exogenously via deposition [38,39], as well as endogenously through demethylation of hair $\mathrm{MeHg}$ to $\mathrm{iHg}$ and absorption of ingested $\mathrm{iHg}$ and inhaled $\mathrm{Hg}^{0}$ vapors that are then incorporated into the growing hair [17,40,41]. The extent and rates of endogenous $\mathrm{iHg}$ accumulation processes are generally low relative to $\mathrm{MeHg}$ uptake in hair $[13,17,42]$.

While these prior studies in ASGM areas suggest that hair THg levels could overestimate dietary $\mathrm{MeHg}$ exposure in the community [43], these studies are not designed to inform population monitoring practices as they used non-random selection of small, convenience samples with limited spatial variability, or they directly targeted individuals involved in gold refining [29]. For example, 5 of the 7 studies had $\mathrm{N}<28$ participants across 1-3 locations (Table S1). A relatively larger study ( $\mathrm{N}=128,6$ communities) entailed a case-control design in which cases were non-randomly selected individuals living in mining communities who were involved in smelting and controls were non-mining individuals living in non-mining communities. None of these study designs allow for understanding of the hair THg biomarker for mining communities where the residents include those not directly engaged in mining or smelting activities.

While extremely elevated gaseous $\mathrm{Hg}$ levels can occur in areas directly outside the gold shops of mining communities [44], the impact of these transient air quality events on inorganic $\mathrm{Hg}$ exposure to the overall population is unknown. Regardless, national biomonitoring programs such as Peru, Colombia, and Uganda exclude hair THg in their population surveillance plans for communities near ASGM due to uncertainties raised in reports that directly studied individuals engaged in amalgam burning. Instead, these programs recommend urine, an accepted biomarker for $\mathrm{iHg}$ exposure, and possibly $\mathrm{THg}$ in blood-a biomarker for recent $\mathrm{MeHg}$ and $\mathrm{iHg}$ exposure and not necessarily long-term exposure. Such policies could fail to identify chronic MeHg exposure risk within populations 
near ASGM areas. Population-relevant evaluations of the hair THg biomarker in ASGM areas are needed to validate the efficacy of this biomarker and to help inform best practices.

This study seeks to understand the efficacy of hair- $\mathrm{THg}$ as a biomarker of $\mathrm{MeHg}$ exposure in population biomonitoring of ASGM regions. To this end, we quantified the relationship between $\mathrm{MeHg}$ and $\mathrm{THg}$ contents in hair for individuals in Madre de Dios, Peru (Figure 1), a region that is an epicenter of ASGM activities in the Amazon basin over the last two decades and has experienced mercury releases to the river environment [45-51]. Mercury exposures to levels that exceed health guidelines have been widely documented for residents of the region [5,12,52-56]. We quantified $\mathrm{THg}$ and $\mathrm{MeHg}$ contents in hair obtained from $\mathrm{N}=287$ individuals (of $\mathrm{N}=2167$ sampled) from 20 communities located within and near the mining region. Approximately half of these individuals were living in ASGM communities where $\mathrm{Hg}$ exposures could be both $\mathrm{MeHg}$ and $\mathrm{iHg}$, and the other half were living in non-mining communities where mercury exposures are presumed to be primarily $\mathrm{MeHg}$ through diet [5,12,52,57]. Single timepoints of exposure as well as temporal, chronic trends were evaluated from communities representing a spectrum of geographic locations and diet, including both native, fish-consuming communities and mining towns populated by migrants from regions where multiple types of dietary protein are consumed.

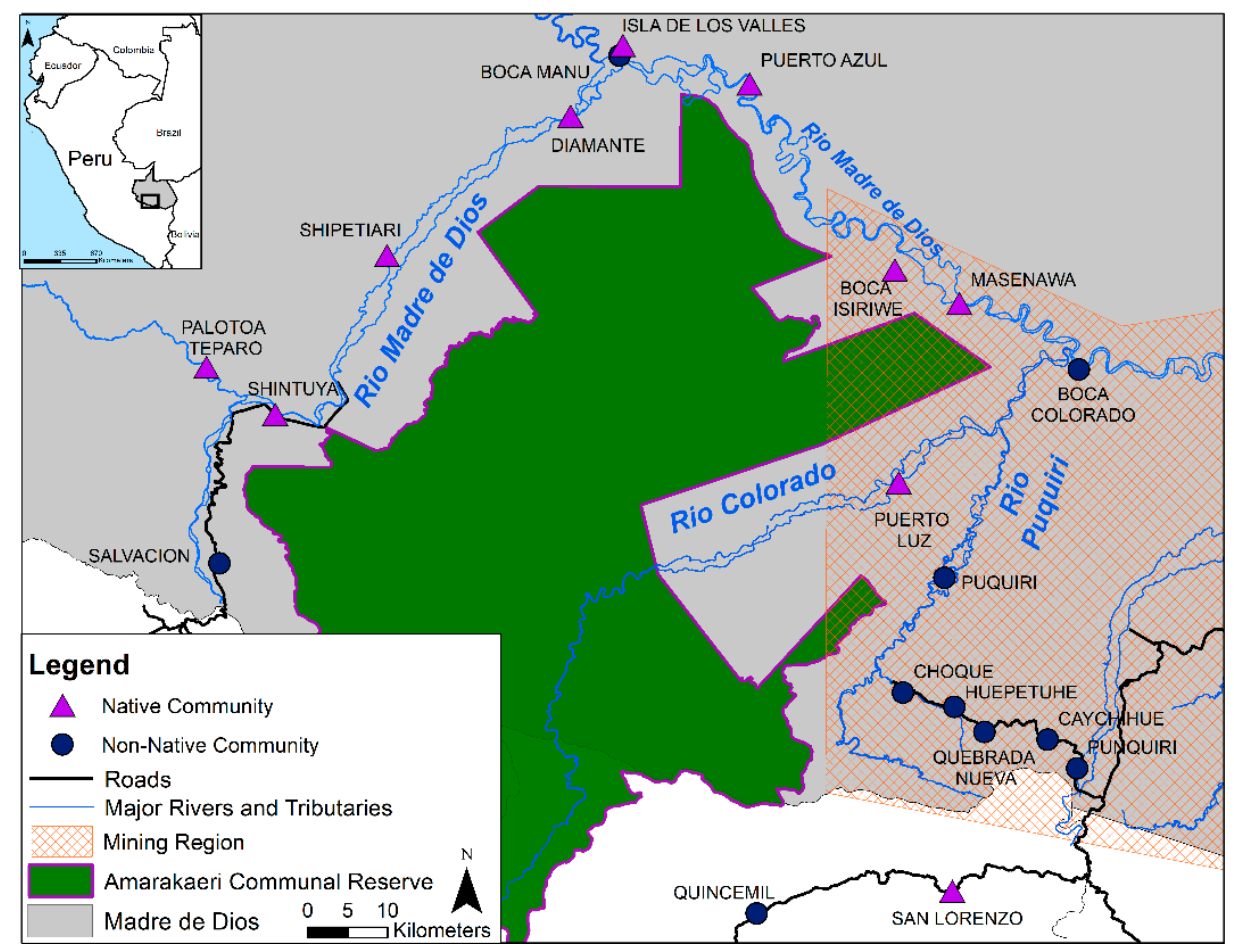

Figure 1. Map of the study area in MDD, Peru. Communities along the river were distinguished based on residence within ASGM (orange hashed zone) or outside ASGM (grey and white zones). Households were visited between 2015 and 2016 for collection of hair samples.

\section{Materials and Methods}

\subsection{Study Design and Sample Collection}

\subsubsection{Population Cohort}

This study is part of our larger parent study [52,53] to evaluate the health status of 23 communities located around the Amarakaeri Communal Reserve along the Madre de Dios and Puquiri Rivers in Southeastern Peru (Figure 1). During March to June 2015, our research team visited 1221 households to collect hair and blood samples, and administer household surveys that included a module on dietary intake from individuals [53]. Households were enrolled if they contained at least one woman of childbearing age (WCBA, 15-49 years). For every 9 households enrolled using this inclusion criteria, a 10th was 
enrolled without that requirement. All members of enrolled households were offered to receive hair THg testing. Within each household, a "sentinel group" was defined consisting of a WCBA and, if applicable, her spouse and her child. More than one sentinel group could be defined within a household depending on household structure. Adults classified in the sentinel group were offered additional mercury blood testing [52,53]. Data collection included a household survey, administered to the economic head of the household, which included questions of individual demographics (age, sex, socioeconomic position), and household food sources. Occupation was initially a 17-category variable in the survey. We later grouped the responses into six categories for ease of computation: mining, agriculture/fishing, other outdoor (e.g., logger, hired labor), professional/urban (e.g., teacher), stay at home/other, and unemployed.

Hair samples were collected from individuals by cutting three tufts of hair from different parts of the occipital region of the scalp. Each tuft was attached to self-adhesive note paper and stored separately in paper envelopes. All samples were stored at ambient conditions and transported to Duke University for analysis.

As noted in our prior publication for the parent study [53], this study was approved by the Committee on Human Ethics from the Universidad Peruana Cayetano Heredia (UPCH) (OHRP registration IORG0000671, IRB00001014, study ID \#63056).

\subsubsection{Subsample Cohort}

This current study is a subset of our parent study: individuals 18 years and older and part of sentinel households. Individuals were selected for $\mathrm{MeHg}$ analysis if they: (a) had blood Hg measurements; (b) had blood polyunsaturated fatty acid measurements (PUFAs, a biomarker possibly linked to diet); and (c) had two remaining intact tufts of hair (of the original three tufts taken). In total, the hair samples of $\mathrm{N}=287$ individuals across 20 communities were selected for $\mathrm{Hg}$ speciation analysis for this study. For data analysis, communities were classified into two distinct geographical regions: within ASGM activity ( $\mathrm{N}=150$ study participants from 10 communities), and outside of ASGM ( $\mathrm{N}=137$ study participants from 10 communities). Community designations as 'within' or 'outside' of mining were defined by the Amazon Conservation Association (Asociación para la Conservación de la Cuenca Amazónica, ACCA). Descriptive statistics of individuals for this study in each region are presented in Table 1 and Table S5. Individuals from indigenous communities and non-indigenous communities were also compared, with indigenous communities shown to be more reliant on fish consumption. Indigenous, or native, communities were defined as those listed on Peru's Ministry of Culture database of indigenous populations at http:/ /bdpi.cultura.gob.pe (Accessed on 1 August 2019). Among the 20 communities represented in this study, 10 were native. Most of the native communities are located outside of mining activity while three are located within mining.

In a subset of 23 individuals, we assessed temporal $\mathrm{MeHg}$ exposure via distal hair segment analysis (Section 2.3). We designated non-migratory status to certain individuals if the person lived in the same community for at least five years, had traveled outside their community less than five days in the last three months, and had no occupational labor outside the community. 


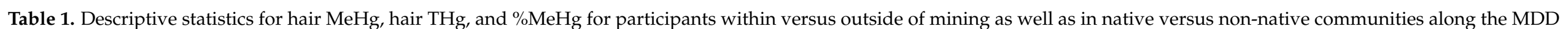

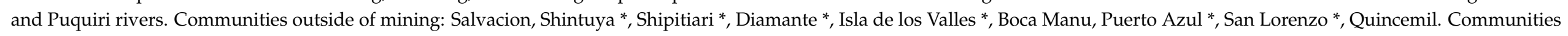
within mining: Masenawa *, Boca Isiriwe* , Boca Colorado, Puerto Luz *, Puquiri, Choque, Huepethue, Querada Nueva, Caychihue, Punquiri. *Native Community.

\begin{tabular}{|c|c|c|c|c|c|c|c|c|c|c|c|c|c|c|}
\hline \multirow{2}{*}{ Location } & \multirow{2}{*}{$\mathbf{n}$} & \multirow{2}{*}{ Males } & \multirow{2}{*}{ Females } & \multirow{2}{*}{ Age (Years) } & \multicolumn{3}{|c|}{$\mathrm{MeHg}(\mu \mathrm{g} / \mathrm{g})$} & \multicolumn{3}{|c|}{$\mathrm{THg}(\mu \mathrm{g} / \mathrm{g})$} & \multicolumn{3}{|c|}{$\% \mathrm{MeHg}$} & \multirow{2}{*}{$\begin{array}{l}\text { Number of Individuals } \\
\text { with \%MeHg }>66 \% \\
\text { (Percentage of } n \text { ) }\end{array}$} \\
\hline & & & & & Min. & Max. & Avg. \pm s.d. & Min. & Max. & Avg. \pm s.d. & Min. & Max. & Avg. \pm s.d. & \\
\hline $\begin{array}{l}\text { Outside } \\
\text { Mining }\end{array}$ & 137 & 38 & 99 & $35.8 \pm 10.4$ & 0.080 & 10.8 & $2.87 \pm 2.45^{*}$ & 0.070 & 10.8 & $3.04 \pm 2.37^{*}$ & 16.0 & 145 & $91.3 \pm 20.0 *$ & $127(92.7 \%)$ \\
\hline $\begin{array}{l}\text { Within } \\
\text { Mining }\end{array}$ & 150 & 46 & 104 & $36.2 \pm 10.9$ & 0.059 & 8.85 & $1.64 \pm 1.58$ & 0.090 & 11.9 & $2.14 \pm 2.08$ & 4.00 & 171 & $81.0 \pm 25.9$ & $121(80.7 \%)$ \\
\hline Native & 88 & 28 & 60 & $33.6 \pm 8.96$ & 0.45 & 10.8 & $3.92 \pm 2.41$ * & 0.403 & 11.3 & $4.15 \pm 2.38^{*}$ & 34.0 & 145 & $93.4 \pm 20.2 *$ & $81(92.0 \%)$ \\
\hline $\begin{array}{c}\text { Non- } \\
\text { Native }\end{array}$ & 199 & 56 & 143 & $37.0 \pm 11.1$ & 0.059 & 8.85 & $1.47 \pm 1.47$ & 0.070 & 11.9 & $1.87 \pm 1.83$ & 4.00 & 171 & $82.6 \pm 24.7$ & $167(83.9)$ \\
\hline Overall & 287 & 84 & 203 & $36.0 \pm 10.6$ & 0.059 & 10.8 & $2.22 \pm 2.13$ & 0.07 & 11.9 & $2.56 \pm 2.27$ & 4.00 & 171 & $86.0 \pm 23.9$ & $248(86.4 \%)$ \\
\hline
\end{tabular}




\subsection{Mercury Analyses in Hair Specimens}

Of the three hair tufts collected from each individual, one was analyzed for $\mathrm{THg}$ content, another tuft analyzed for $\mathrm{MeHg}$, and the third was saved for potential future analyses. Both measurements were performed on the proximal $2 \mathrm{~cm}$ segments of each hair tuft (unwashed), which corresponds to exposure over the most recent two-month period before sample collection [23]. We chose not to wash the hair samples because washing procedures have been reported to leach mercury compounds incorporated into the hair at the follicle, resulting in underestimation of hair mercury content [58-63].

$\mathrm{THg}$ data for proximal segments from this population were reported by Weinhouse et al. [53]. For all other segments processed for this study, THg content was determined using the same methods, by thermal decomposition, amalgamation, and atomic absorption detection (Milestone DMA-80). The instrument was calibrated with dilutions of a certified $1 \mathrm{mg} /$ L Methylmercury Standard (Brooks Applied Labs, Bothell, WA, USA). Calibration was verified by running a hair certified reference material (CRM DB001, European Reference Materials) after every 10 to 15 samples. Sample measurements were accepted if the subsequent analysis of the CRM was within $10 \%$ of the certified mean value. The average recovery of the $\mathrm{THg}$ reference value in the CRM was $98 \% \pm 6.9 \%(\mathrm{~N}=308)$ (SI Section $\mathrm{S} 2$, Figure S1). Additional information on the uncertainty of $\mathrm{THg}$ measurements is provided in the SI Section S3.

$\mathrm{MeHg}$ content was determined by extraction with tetramethylammonium hydroxide [21], followed by analysis of extracts by aqueous phase ethylation, purge-trap on Tenax resin and gas chromatographic separation (BrooksRand MerxM), and inductively coupled plasma mass spectrometry (Agilent 7700). Duplicate extractions of hair reference material (RM; International Atomic Energy Agency 086) were performed in parallel with each batch of samples. An aliquot of stable $\mathrm{MeHg}$ isotope $\left(\mathrm{CH}_{3}{ }^{201} \mathrm{HgCl}\right)$ was added as an internal standard (IS) to each RM and hair sample prior to the extraction step. Measured $\mathrm{MeHg}$ values of the RM were $99 \% \pm 8.4 \%(\mathrm{~N}=50)$ of the reference value, after adjustment of the measured IS (Figure S2B). For the hair samples, the average IS recovery was $82 \% \pm 14 \%$ for proximal hair segments and $93 \% \pm 18 \%$ for distal hair segments (Figure S4). Additional descriptions and results of instrument calibration verification, IS recoveries, RM analyses, and measurement uncertainty are presented in SI Sections S2 and S3.

\subsection{Intra-Individual Variation Evaluated with Distal Hair Segment Analyses}

After analysis, we observed that for several samples, the measured MeHg relative to measured $\mathrm{THg}$ (expressed as \% MeHg) was over 100\% (Figure 2). We hypothesized that this was due to analyzing $\mathrm{MeHg}$ and $\mathrm{THg}$ on separate tufts of hair. Note that variation of hair mercury content is expected on different parts of an individual's scalp, which may contribute to intra-individual differences in the data. We therefore performed an additional analysis for selected individuals with long hair samples (from female individuals) in which the two tufts were combined into a single composite sample that was then cut into $2-\mathrm{cm}$ segments along the entire length of hair. These $2-\mathrm{cm}$ segments were then apportioned for analysis of $\mathrm{MeHg}$ and $\mathrm{THg}$ using the methods described above.

Distal hair segment analyses were performed for $\mathrm{N}=23$ individuals from two communities: the mining community Huepetuhe (HHU) $(\mathrm{N}=15)$ and the non-mining, native community Diamante (HDM) $(\mathrm{N}=8)$. The individuals within each community were selected to obtain a spectrum of proximal $\% \mathrm{MeHg}$ values grouped into three categories: $\% \mathrm{MeHg}<66 \%(\mathrm{~N}=6) ; 66 \% \leq \% \mathrm{MeHg} \leq 102 \%(\mathrm{~N}=9) ; \% \mathrm{MeHg}>102 \%(\mathrm{~N}=8)$, which correspond to $\% \mathrm{MeHg}$ values below, within, and above the $\% \mathrm{MeHg}$ reference range, respectively (See Reference Hair \%MeHg Range in Section 2.4.1 for explanation of these thresholds). $\mathrm{THg}$ and $\mathrm{MeHg}$ contents in composited distal hair segments were performed to understand potential discrepancies introduced in the analysis of non-composite proximal segments for $\mathrm{THg}$ and $\mathrm{MeHg}$ contents. 


\subsection{Statistical Analyses}

Descriptive statistics with the median, range, and mean were used to describe the study population. Significant differences in hair $\mathrm{THg}, \mathrm{MeHg}$, and \% $\mathrm{MeHg}$ between community types (native vs. non-native and within vs. outside of mining) were evaluated with either a Student or Welch two-sample $t$-test at the level $\alpha<0.95$. Hair THg was compared to the U.S. Environmental Protection Agency's (EPA) reference level of $1.0 \mu \mathrm{g} / \mathrm{g}$ [19]. The proportion of individuals exceeding this limit was reported by native/non-native, as well as location relative to mining region (i.e., within versus outside).

\subsubsection{Reference Hair \%MeHg Range}

To compare the accuracy of hair $\mathrm{THg}$ as a predictor for $\mathrm{MeHg}$ in these dual exposure communities, the $\% \mathrm{MeHg}$ values were compared to values expected for a control population exposed solely to $\mathrm{MeHg}$ through diet. The pooled mean \pm standard deviation of hair \% MeHg measurements was $84 \% \pm 18 \%$ for fish-consuming populations in Belgium [30], Brazil [26,31,35], Yugoslavia [32], Iraq [33], Spain [34,36], and France [22] (Table S2). Thus, we grouped individuals into categories within or outside the range of $66-102 \%$ for $\% \mathrm{MeHg}$ (i.e., the "expected" range if individuals were only exposed to mercury through fish consumption).

\subsubsection{Predictors of Hair $\mathrm{THg}$, Hair $\mathrm{MeHg}$, and \% $\mathrm{MeHg}$}

Household survey data for sex, age, occupation, nativity, and location relative to mining were treated as categorical variables (SI Section S5, Table S6). We first tested bivariate associations between each predictor variable and outcomes hair $\mathrm{THg}$, hair $\mathrm{MeHg}$, and $\% \mathrm{MeHg}$ (Tables S7-S9). Variables with associations of $p<0.20$ were included in a multivariate linear regression model. Random intercepts were used to control for correlation within communities. The distributions of all outcome variables were right skewed; thus, natural $\log$ transformation was used in all analyses.

Local join count tests were performed in GeoDa (v1.18) to test for spatial clustering of individuals in mining regions with \% MeHg values above and below the expected threshold. Logistic regressions were also performed to understand other variables associated with these individuals. We calculated the odds ratio and probability that an individual exhibits hair $\% \mathrm{MeHg}<66 \%$ for each of the predictor variables described above. Random intercepts were used to control for correlation within communities. Predictor variables were included in the final multivariate analysis if the bivariate association tested had a $p<0.20$.

\subsubsection{Hair THg-Hair MeHg Correlations}

Pearson correlations were computed between natural log-transformed hair THg and natural log-transformed hair MeHg values. Correlations were performed for all individuals as well as for individuals grouped by nativity, location relative to mining, and community.

\section{Results}

\subsection{Differences in Hair $\mathrm{THg}, \mathrm{MeHg}$, and \% $\mathrm{MeHg}$ Contents between Communities}

For the subsample selected for this study, the median THg value in the proximal $2-\mathrm{cm}$ hair segments was $1.51 \mu \mathrm{g} / \mathrm{g}$ (range 0.090-11.9 $\mu \mathrm{g} / \mathrm{g}$ ) and $2.55 \mu \mathrm{g} / \mathrm{g}$ (range 0.070-10.8 $\mu \mathrm{g} / \mathrm{g}$ ) for residents living within $(\mathrm{N}=150)$ and outside $(\mathrm{N}=137)$ of mining communities, respectively (Table 1, Figure 2B).These THg values correspond to $71 \%$ and $80 \%$ of the residents living within and outside of mining surpassing the US EPA threshold value of $1.0 \mu \mathrm{g} / \mathrm{g}$ hair THg, respectively. Median hair MeHg contents were $1.14 \mu \mathrm{g} / \mathrm{g}$ (range 0.059-8.85 $\mu \mathrm{g} / \mathrm{g}$ ) and $1.97 \mu \mathrm{g} / \mathrm{g}$ (range $0.080-10.8 \mu \mathrm{g} / \mathrm{g}$ ) for individuals living within and outside mining, respectively (Table 1, Figure 2A). We observed the median percentage of hair $\mathrm{THg}$ as $\mathrm{MeHg}$ (\%MeHg) was 82\% (range 4-171\%) for individuals within mining and 91\% (range 16-145\%) for individuals outside of mining (Table 1, Figure 2C). 

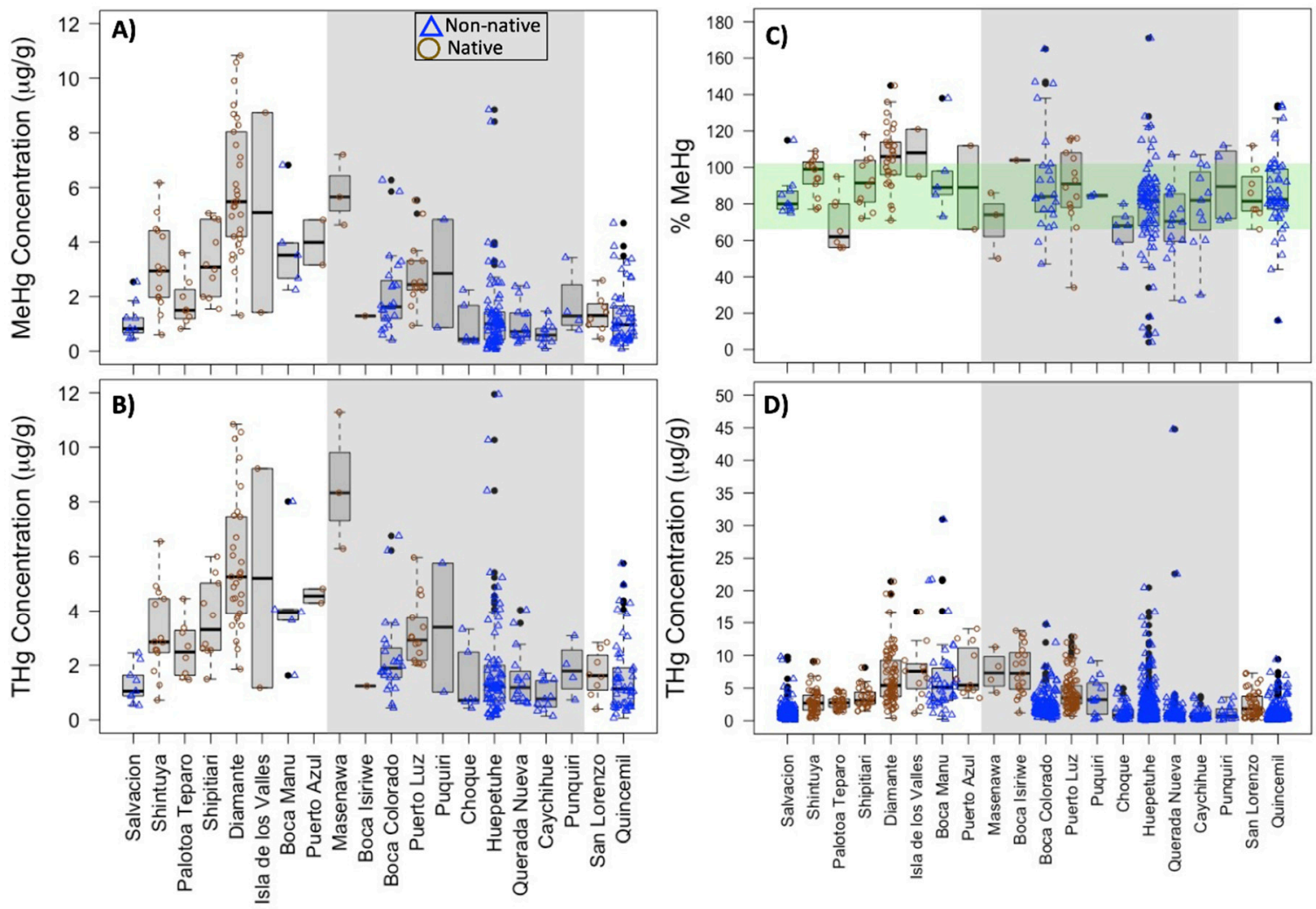

Figure 2. (A) $\mathrm{MeHg}$, (B) $\mathrm{THg}$, and (C) the \% of $\mathrm{THg}$ as $\mathrm{MeHg}$ in the hair for individuals ( $N=287$ ) living in communities around the Amaerakari Reserves in Madre de Dios, Peru. These individuals are a subset from the larger parent study $(\mathrm{N}=1543)$ [53] with hair $\mathrm{THg}$ distribution shown in (D). Measurements were performed on the proximal 2-cm hair segment. Symbols represent measurements of individual participants and are grouped by their residence in native (open brown circles) and non-native (open blue triangles) communities. Communities in the grey shaded region lie within mining. In part (C), the light green shaded region represents the expected range of $\% \mathrm{MeHg}$ values, based on prior studies of $\mathrm{Hg}$ exposure for individual exposed to mercury only through diet. The black bars represent the median hair concentrations for each community, the box outline represents values in the 25th to 75th percentile, the whiskers represent values outside the middle $50 \%$, and the closed black circles represent data points that are outliers of each community distribution.

While \%MeHg values are theoretically bound between 0 and $100 \%$, subsequent sensitivity analysis attributed $\% \mathrm{MeHg}$ values over $100 \%$ to intra-individual variation in hair samples (see SI Sections S3 and S4). For eight individuals with \%MeHg values of $105-170 \%$ in non-homogenized proximal hair segments, the adjacent homogenized distal segment had \%MeHg values in the expected range (66-103\% MeHg) (Figure S6). In contrast, five out of six individuals with $\% \mathrm{MeHg}$ below $66 \%$ in the proximal segment also had $<66 \% \mathrm{MeHg}$ in the homogenized distal segment. Variation of $\mathrm{THg}$ content across three different hair tufts appeared to explain \% MeHg values exceeding the $66-102 \%$ expected range.

The individuals living near mining activity may have experienced mercury exposures from both inorganic and organic $\mathrm{Hg}$ sources. Regardless, median \% $\mathrm{MeHg}$ values for all communities are within the expected range $(66 \%$ to $102 \%$ shown in the green shaded area of Figure 2C) based on populations with dietary $\mathrm{MeHg}$ as the sole exposure source (Table S2) [22,64]. Using $>66 \% \mathrm{MeHg}$ as a cutoff, we observed that 127 out of 137 people outside of mining $(92.7 \%)$ and 121 out of 150 people within mining $(80.7 \%)$ had $\mathrm{MeHg}$ as the predominant form of $\mathrm{THg}$ in their hair (Table 1).

\subsection{Other Demographic Variables Associated with Exposure}

To further assess the efficacy of hair $\mathrm{THg}$ as a predictor for $\mathrm{MeHg}$ exposure, mixed effect models were used to evaluate if other demographic variables were correlated with 
$\mathrm{THg}, \mathrm{MeHg}$, and \%MeHg values. Residence in a native community was associated with 2.18 (95\% CI: 1.38-3.35) and 2.22 (95\% CI: 1.23-3.67) times higher hair THg and $\mathrm{MeHg}$ content than non-native communities, respectively (Tables S7 and S8). The significance of nativity in both the parent study [53] and in this subset population further support that consumption of contaminated fish (potentially from ASGM-related mercury discharge) is a main source of exposure for indigenous individuals.

Residence within/outside of mining, age, and occupation were not significantly associated with hair MeHg (Table S8, Figure S9) or hair THg (Table S7, Figure S8) at the 0.05 level. However, sex was a significant factor associated with $\mathrm{THg}$ in hair, predicting $24 \%$ lower hair THg levels in females compared to males (95\% CI: 6.3-29.3\%).

Importantly, correlations between $\% \mathrm{MeHg}$ and demographic variables could inform efficacy of the THg hair biomarker for MeHg exposure. Given our observations of higher hair MeHg levels in native communities, residence in a non-native community within mining was hypothesized to contribute to a lower $\% \mathrm{MeHg}$ due to potential for inorganic $\mathrm{Hg}$ exposure in these areas. However, native ethnicity was not a significant predictor of $\% \mathrm{MeHg}$. In fact, none of the variables included in the multivariate analysis for $\% \mathrm{MeHg}$ (nativity, residence within mining, and occupation) were significant at the 0.05 level (Table S9, Figure S10). Residence within mining was a significant predictor for $\% \mathrm{MeHg}(p<$ 0.05 ) in the bivariate analysis but was not significant in the multivariate model.

\subsection{Factors Associated with Low \%MeHg Values in Hair in Mining Communities}

Spatial analyses and logistic regressions were performed to understand factors that may differentiate individuals within mining communities whose $\% \mathrm{MeHg}$ values were above and below the $66 \%$ threshold. The demographics of these two subsets are presented in Table 2, and both groups demonstrated comparable characteristics. We hypothesized that, for each community, individuals with less than $66 \% \mathrm{MeHg}$ may be clustered geographically (i.e., located near a gold smelting shop). Although we could not test spatial clustering of $\mathrm{MeHg}$ distributions as a function of gold shop locations since these locations were not available, join count statistics indicated no significant clustering of individuals living in Huepetuhe, Caychihue, or Boca Colorado $(p>0.05)$. 
Table 2. Demographics of individuals within mining, separated by those with hair $\% \mathrm{MeHg}<66 \%$ and those with hair $\% \mathrm{MeHg} \geq 66 \%$. Sex, age, nativity, and occupation were used as predictor variables in the logistic regressions.

\begin{tabular}{|c|c|c|c|c|}
\hline \multirow[t]{2}{*}{ Variable } & \multicolumn{2}{|c|}{$\% \mathrm{MeHg}<66 \%(\mathrm{~N}=29)$} & \multicolumn{2}{|c|}{$\% \mathrm{MeHg} \geq 66 \%(\mathrm{~N}=121)$} \\
\hline & $\mathbf{N}$ & $\%$ & $\mathbf{N}$ & $\%$ \\
\hline \multicolumn{5}{|l|}{ Sex } \\
\hline Male & 12 & 41 & 34 & 28 \\
\hline Female & 17 & 59 & 87 & 72 \\
\hline \multicolumn{5}{|l|}{ Age } \\
\hline$<31$ & 10 & 34 & 43 & 36 \\
\hline $31-50$ & 14 & 48 & 51 & 42 \\
\hline$>50$ & 5 & 18 & 27 & 22 \\
\hline \multicolumn{5}{|l|}{ Native Ethnicity } \\
\hline Yes & 2 & 7 & 15 & 12 \\
\hline No & 27 & 93 & 106 & 88 \\
\hline \multicolumn{5}{|l|}{ Occupation } \\
\hline Mining & 1 & 3 & 12 & 10 \\
\hline Agriculture/Fishing & 2 & 7 & 4 & 3 \\
\hline Other Outdoor & 1 & 3 & 4 & 3 \\
\hline Professional/Urban & 6 & 21 & 41 & 34 \\
\hline Self-employed/Other & 5 & 18 & 22 & 18 \\
\hline No Job/Not Reported & 14 & 48 & 38 & 32 \\
\hline \multicolumn{5}{|l|}{ Length of Residence } \\
\hline Born Here & 4 & 14 & 19 & 16 \\
\hline$\leq 5$ years & 4 & 14 & 20 & 17 \\
\hline$>5$ years & 16 & 54 & 73 & 60 \\
\hline NA & 5 & 18 & 9 & 7 \\
\hline
\end{tabular}

Logistic regressions, however, indicated that sex and certain occupations were associated with individuals exhibiting \%MeHg less than 66\% (Table S10, Figures S11 and S12). Females had 0.25 -times lower odds of having $\% \mathrm{MeHg}<66 \%$ than males. This is consistent with the fact that males made up $41 \%$ of individuals with $\% \mathrm{MeHg}<66 \%$, despite representing only $30 \%$ of the within mining sample population (Table 2 ). This could, perhaps, be due to males in the household being more likely to work outside of the home, resulting in increased exposure to $\mathrm{iHg}$ in the atmosphere. Individuals with occupations in mining or professional/urban occupations had 0.13- and 0.25-times lower odds of having hair $\% \mathrm{MeHg}<66 \%$ than unemployed individuals, respectively. The mining process consists of many steps, not all of which involve direct work with $\mathrm{Hg}^{0}{ }_{\mathrm{L}}$, which may explain the miners with lower odds of exposure $[65,66]$. Additionally, many miners operate illegally [67], so it is possible that individuals would not accurately report their occupation on the survey.

\subsection{Hair $\mathrm{THg}$ as a Predictor of Hair $\mathrm{MeHg}$ Exposure}

The observation of subgroups with mixed mercury exposure raises a question about the utility of hair $\mathrm{THg}$ as a population biomonitoring tool for $\mathrm{MeHg}$ exposure for mining communities. To answer this question, we first tested for correlation between hair $\mathrm{THg}$ and $\mathrm{MeHg}$ contents for mining and non-mining communities (Table S11, Figure 3). High correlations between hair $\mathrm{THg}$ and $\mathrm{MeHg}$ would indicate hair $\mathrm{THg}$ to be consistent with $\mathrm{MeHg}$ levels in hair (and $\mathrm{MeHg}$ brain burdens). We hypothesized that hair $\mathrm{MeHg}-\mathrm{THg}$ correlations would be high $(r>0.7)$ in native communities and in communities outside of mining due to individuals primarily being exposed to $\mathrm{MeHg}$ via diet. Conversely, $\mathrm{MeHg}$ $\mathrm{THg}$ correlations were hypothesized to be low $(\mathrm{r}<0.5)$ in communities within mining due to multiple $\mathrm{Hg}$ species exposures (i.e., some of the total mercury would be present as $\mathrm{iHg})$. Contrary to this hypothesis, significant positive correlations $(r>0.7)$ were found for populations both within and outside of mining, as well as for native and non-native communities (Figure 3). Moreover, the correlation coefficients for the within and outside 
of mining groups were not significantly different from one another $(p=0.261)$, indicating that the relationship between hair THg and hair $\mathrm{MeHg}$ were the same in mining and non-mining towns. Further examination of each community also showed significantly high correlations for 15 of 16 communities. The sample size for four of the communities was insufficient for this analysis. These results were in agreement with previous reports of strong hair MeHg-THg correlations in communities near mining activity in Brazil [68].
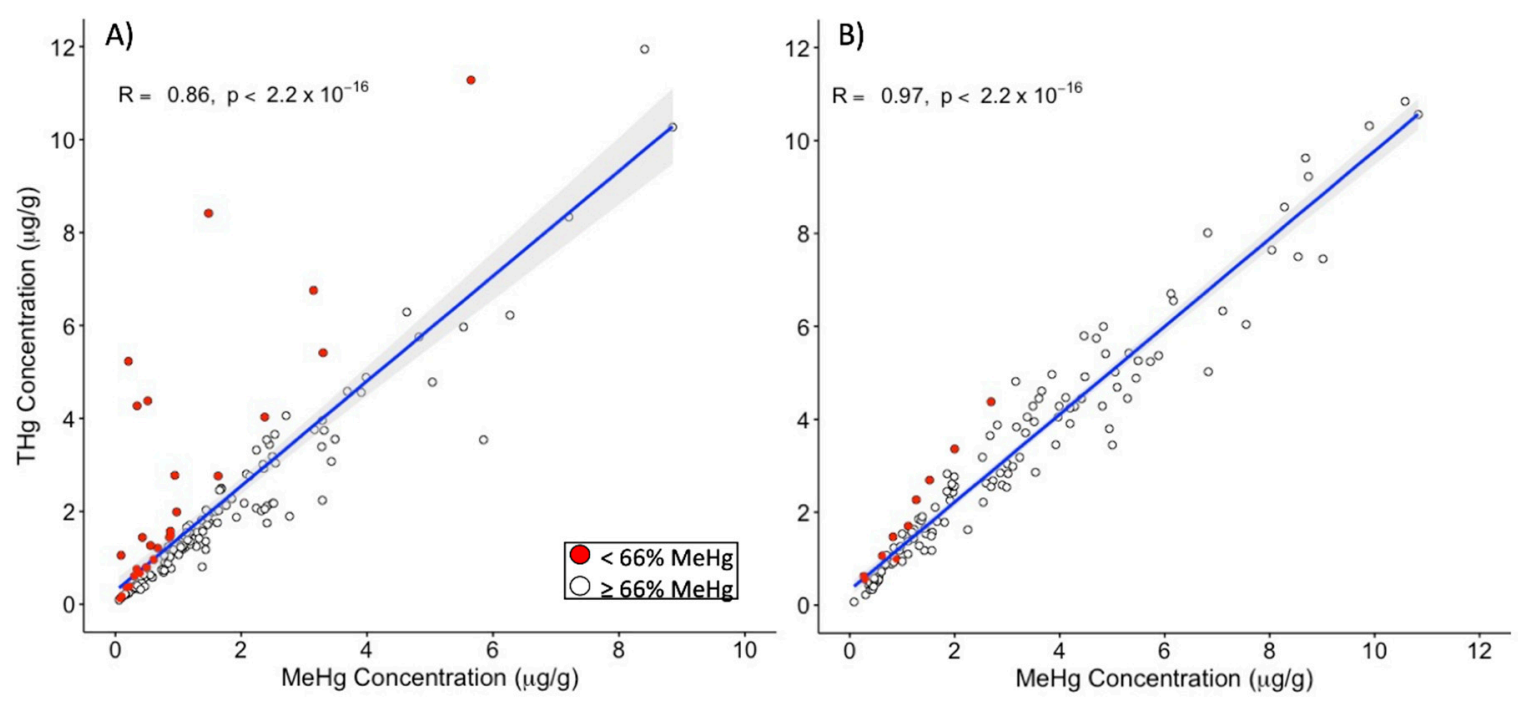

Figure 3. Scatterplots of Pearson correlations between hair $\mathrm{THg}$ and $\mathrm{MeHg}$ for individuals living within mining activity (A) and outside of mining activity (B). The blue line indicates a linear trend with the $95 \%$ confidence interval shaded in grey. Individuals with hair $\% \mathrm{MeHg}<66 \%$ are highlighted in red.

\subsection{Subsample Selection Bias and Comparisons}

This study entailed a selected subsample $(\mathrm{N}=287)$ of the parent cohort study ( $\mathrm{N}$ $=1543$ ), and demographics of the subsample are comparable to the larger cohort. Both populations exhibited similar distributions with respect to sex, age, residence within mining, nativity, and occupation (Table S6). Individuals not selected from the parent cohort into the subsample did not significantly differ by THg exposure $(t=0.170, \mathrm{df}=605.9$, $p=0.865)$ or $\operatorname{sex}\left(\chi^{2}=0.236, p=0.627\right)$, further suggesting that the subsample likely does not have selection bias.

Our results also suggest that the exposure trends in the subset selected for this study are comparable to those of the larger cohort study, which found residence in a native community as a significant factor associated with $\mathrm{THg}$ in hair, predicting 1.9 times higher hair THg levels than non-native communities [53]. In this study, we similarly found that residence in a native community predicted 2.18 (95\% CI: 1.38-3.35) times higher hair $\mathrm{THg}$ levels than non-native communities (Table S7). In both studies, residence within/outside of mining, age, and occupation were not significantly associated to hair $\mathrm{THg}$ at the 0.05 level (Table S7, Figure S8). In this sub-study, however, sex was a significant factor associated with THg in hair, predicting $24 \%$ lower hair THg levels in females compared to males $(95 \%$ CI: $6.3-29.3 \%)$.

\section{Discussion}

This study demonstrates that the use of hair total mercury content is a valid biomarker for public health monitoring of MeHg exposure in both ASGM and non-ASGM communities. While total hair mercury alone is not sufficient to capture all forms of mercury exposure, this research shows that excluding hair $\mathrm{THg}$ assessments without an alternative biomarker for $\mathrm{MeHg}$ exposure could lead to significant underestimation of population exposure risks. As such, this study could alleviate uncertainty concerns for the use of hair $\mathrm{THg}$ for community biomonitoring of MeHg exposure in ASGM areas [1,58,59]. 
Here, we observed approximately $20 \%$ of the individuals residing within mining to have low hair \%MeHg. Because these individuals represented a small percentage of the population, they did not alter population level trends for relative $\mathrm{MeHg}$ content in hair. Furthermore, we observed a nominal contribution of community location relative to mining activity as a predictor for \% $\mathrm{MeHg}$ values and also observed strong hair $\mathrm{MeHg}-\mathrm{THg}$ correlations for populations near mining. Altogether, these data support the use of hair $\mathrm{THg}$ as a population monitoring tool for MeHg exposure for Madre de Dios communities near mining activity.

Our conclusion differs from previous studies, suggesting that the hair $\mathrm{THg}$ biomarker overestimates $\mathrm{MeHg}$ exposure for individuals living near ASGM activity [21,22,24,69]. The discrepancy between our study and others exists for several reasons. First, the previous studies relied on small convenience samples (i.e., purposefully sampled individuals) of predominantly miners from the same communities, indicating that the study groups represented only a fraction of those at risk to mercury exposure and are not generalizable to the communities in which they live. Second, in our study, all communities reside within the same watershed, and regardless of mining activity, rely on the same local fish populations for dietary protein. As a result, for communities within the same watershed, hair $\mathrm{THg}$ correlates with $\mathrm{MeHg}$ exposure at the community level, regardless of nativity or location relative to mining.

While our results support the use of hair $\mathrm{THg}$ for public health monitoring of $\mathrm{MeHg}$ exposure in ASGM-impacted regions, the small subset of individuals with low \% $\mathrm{MeHg}$ confirms exposure to multiple $\mathrm{Hg}$ sources (i.e., inorganic and organic) in the mining communities. As such, we recommend coupling THg hair with a companion biomarker for iHg exposure (i.e., urine [70]) for both organic and inorganic mercury exposure monitoring.

The implications of this study are relevant due to the implementation of the Minamata Convention and related efforts to improve public health assessments of mercury exposure. Several articles of the Convention emphasize development of methods to identify at-risk populations, as well as to evaluate the long-term effectiveness of the Convention in terms of reducing mercury exposure [23,71]. Population biomonitoring is therefore needed to understand mercury exposure trends [72], and governmental agencies of signatory nations are currently evaluating options and updating their policies for assessing mercury exposures in their populations [73]. Such polices for populations living near ASGM activity can be especially challenging because of the risks of exposure to multiple $\mathrm{Hg}$ species. International public health guidelines $[1,4,58,59]$ for mercury biomonitoring currently recommend hair $\mathrm{THg}$ for populations where dietary $\mathrm{MeHg}$ is the major route of mercury exposure. Hair is advantageous over other biospecimens because it represents a timeintegrated exposure, can be non-invasively collected, and is relatively easy to handle and analyze (compared to liquid specimens). However, these same international public health guidelines also express caution for the use of the hair THg biomarker in the ASGM context $[1,4,60,61]$. Such cautionary messaging may be discouraging the collection of the hair THg biomarker in ASGM regions without the replacement of alternative measures such as $\mathrm{MeHg}$ in hair or blood that require specialized equipment and technical training and may not be feasible in cost-constrained areas.

Such biomonitoring practices that exclude hair $\mathrm{THg}$ analyses without another biomarker of $\mathrm{MeHg}$ exposure are contributing to a scarcity of $\mathrm{MeHg}$ exposure data in regions hosting ASGM activity and possibly an overreliance on urine $\mathrm{THg}$ for identification of populations vulnerable to mercury exposure. In our study, 106 out of 150 individuals living in mining communities had hair THg $>1 \mu \mathrm{g} / \mathrm{g}$ (the EPA reference level), and 88 of these people had $\% \mathrm{MeHg}>66 \%$ for their hair. According to our data, sole reliance of urine $\mathrm{THg}$ for monitoring mercury exposure in mining communities would have misclassified approximately $59 \%$ of the population (i.e., 88 out of 150 ) as having low mercury exposure. This misclassification, combined with MeHg exposure having deleterious health effects, would significantly underestimate population exposure risks. 


\section{Conclusions}

This study supports the use of hair $\mathrm{THg}$ for monitoring $\mathrm{MeHg}$ exposure of populations in mining regions where alternative $\mathrm{MeHg}$ exposure biomarkers are not feasible. We emphasize that our study does not advocate the sole use of hair THg as a biomarker of total mercury exposure (organic + inorganic $\mathrm{Hg}$ ) in population biomonitoring. Rather, the collection of hair $\mathrm{THg}$ could supplement urine $\mathrm{THg}$, the current recommended biomarker for communities near ASGM [3,4], and would provide a fuller picture of $\mathrm{MeHg}$ and $\mathrm{iHg}$ exposures in the community. We also note that for a subset of individuals in this study, hair THg also exhibited changes over distal hair segments, indicating changes in mercury exposures over time. Thus, temporal variability should be taken into consideration when interpreting exposure data. Overall, these results support the use of hair as an acceptable matrix for assessing community MeHg exposure near ASGM sites and underscore the importance of population-representative studies for use in biomonitoring programs.

Supplementary Materials: The following Supplementary Information (SI) is available online at https:/ / www.mdpi.com/article/10.3390/ijerph182413350/s1, SI Section S1: Hair Hg biomarker data from previous reports; SI Section S2: MeHg analysis methods; SI Section S3: Measurement uncertainties; SI Section S4: Hair Segment Data; SI Section S5: Statistical Analyses.

Author Contributions: F.K., C.W., W.K.P. and H.H.-K. designed this study. W.K.P., E.J.O., A.J.B. and A.M.M. designed and led the 2015 parent study and sample collection. F.K. performed the sample and data analysis and led the writing of the manuscript with guidance from all co-authors. E.M.P., W.K.P. and H.H.-K. contributed funding acquisition and project administration. All authors have read and agreed to the published version of the manuscript.

Funding: This work was funded by the National Institute of Environmental Health Sciences (NIEHS) Superfund Research Program (P42ES010356) and Hunt Oil Peru LLC (HOEP-QEHSS-140003). FAK was also partially supported by the Oak Ridge National Laboratory GO program (Task Order 4000150576).

Institutional Review Board Statement: This study was approved by the Committee on Human Ethics from the Universidad Peruana Cayetano Heredia (UPCH) (OHRP registration IORG0000671, IRB00001014, study ID \#63056). Informed consent was obtained from all participants.

Informed Consent Statement: Informed consent was obtained from all subjects involved in the study.

Data Availability Statement: The data presented in this study are available on request from the corresponding author.

Conflicts of Interest: The authors declare no conflict of interest. The funders had no role in the design of the study; in the collection, analyses, or interpretation of data; in the writing of the manuscript, or in the decision to publish the results.

\section{References}

1. UN Environment Programme. Global Mercury Assessment 2018; United Nations: Geneva, Switzerland, 2018.

2. Veiga, M.M.; Angeloci-Santos, G.; Meech, J.A. Review of barriers to reduce mercury use in artisanal gold mining. Extr. Ind. Soc. 2014, 1, 351-361. [CrossRef]

3. Evers, D.C.; Keane, S.E.; Basu, N.; Buck, D. Evaluating the effectiveness of the minamata convention on mercury: Principles and recommendations for next steps. Sci. Total Environ. 2016, 569, 888-903. [CrossRef]

4. UN Environment Programme. UNEP/MC/COP.3/14-Report of the Ad Hoc Technical Expert Group for Effectivess for Evaluation: Proposed Framework for the Effectiveness Evaluation of the Minamata Convention on Mercury; United Nations: Geneva, Switzerland, 2019.

5. Feingold, B.J.; Berky, A.; Hsu-Kim, H.; Rojas, E.; Pan, W.K. Population-based dietary exposure to mercury through fish consumption in the Southern Peruvian Amazon. Environ. Res. 2019, 183, 108720. [CrossRef] [PubMed]

6. Hacon, S.D.; Oliveira-Da-costa, M.; Gama, C.D.; Ferreira, R.; Basta, P.C.; Schramm, A.; Yokota, D. Mercury exposure through fish consumption in traditional communities in the Brazilian Northern Amazon. Int. J. Environ. Res. Public Health 2020, 17, 5269. [CrossRef] 
7. Salazar-Camacho, C.; Salas-Moreno, M.; Marrugo-Madrid, S.; Marrugo-Negrete, J.; Díez, S. Dietary human exposure to mercury in two artisanal small-scale gold mining communities of Northwestern Colombia. Environ. Int. 2017, 107, 47-54. [CrossRef] [PubMed]

8. Straaten, P. Mercury contamination associated with small-scale gold mining in Tanzania and Zimbabwe. Sci. Total Environ. 2000, 259, 105-113. [CrossRef]

9. Mason, R.P.; Baumann, Z.; Hansen, G.; Yao, K.M.; Coulibaly, M.; Coulibaly, S. An assessment of the impact of artisanal and commercial gold mining on mercury and methylmercury levels in the Environment and Fish in Cote d'Ivoire. Sci. Total Environ. 2019, 665, 1158-1167. [CrossRef] [PubMed]

10. Appleton, J.D.; Williams, T.M.; Breward, N.; Apostol, A.; Miguel, J.; Miranda, C. Mercury contamination associated with artisanal gold mining on the island of Mindanao, the Philippines. Sci. Total Environ. 1999, 228, 95-109. [CrossRef]

11. Limbong, D.; Kumampung, J.; Rimper, J.; Arai, T.; Miyazaki, N. Emissions and environmental implications of mercury from artisanal gold mining in North Sulawesi, Indonesia. Sci. Total Environ. 2003, 302, 227-236. [CrossRef]

12. Wyatt, L.; Ortiz, E.J.; Feingold, B.; Berky, A.; Diringer, S.; Morales, A.M.; Jurado, E.R.; Hsu-Kim, H.; Pan, W. Spatial, temporal, and dietary variables associated with elevated mercury exposure in peruvian riverine communities upstream and downstream of artisanal and small-scale gold mining. Int. J. Environ. Res. Public Health 2017, 14, 1582. [CrossRef] [PubMed]

13. National Research Council. Toxicological Effects of Methylmercury; The National Academies Press: Washington, DC, USA, 2000. [CrossRef]

14. Syversen, T.; Kaur, P. The toxicology of mercury and its compounds. J. Trace Elem. Med. Biol. 2012, 26, 215-226. [CrossRef] [PubMed]

15. Driscoll, C.T.; Mason, R.P.; Chan, H.M.; Jacob, D.J.; Pirrone, N. Mercury as a global pollutant: Sources, pathways, and effects. Environ. Sci. Technol. 2013, 47, 4967-4983. [CrossRef] [PubMed]

16. Drasch, G.; Wanghofer, E.; Roider, G. Are blood, urine, hair, and muscle valid biomonitors for the internal burden of men with the heavy metals mercury, lead and cadmium? An investigation on 150 deceased. Trace Elem. Electrocytes 1997, 14, 116-123.

17. Cernichiari, E.; Myers, G.J.; Ballatori, N.; Zareba, G.; Vyas, J.; Clarkson, T. The biological monitoring of prenatal exposure to methylmercury. Neurotoxicology 2007, 28, 1015-1022. [CrossRef]

18. Clarkson, T.W. Mechanisms of mercury disposition in the body. Am. J. Ind. Med. 2007, 764, 757-764. [CrossRef] [PubMed]

19. Agency for Toxic Substances and Disease Registry (ASTDR). Toxicological Profile for Mercury; US Department of Health and Human Services: Atlanta, GA, USA, 1999.

20. UN Environment Programme. Minamata Convention on Mercury. UNEP/MC/COP.4/INF/12—Guidance on Monitoring of Mercury and Mercury Compounds to Support the Effectiveness Evaluation of the Minamata Convention; United Nations: Geneva, Switzerland, 2021.

21. Laffont, L.; Maurice, L.; Amouroux, D.; Navarro, P.; Monperrus, M.; Sonke, J.E.; Behra, P. Mercury speciation analysis in human hair by species specific isotope dilution using GC-ICP-MS. Anal. Bioanal. Chem. 2013, 405, 3001-3010. [CrossRef]

22. Laffont, L.; Sonke, J.E.; Maurice, L.; Monrroy, S.L.; Chincheros, J.; Amouroux, D.; Behra, P. Hg Speciation and stable isotope signatures in human hair as a tracer for dietary and occupational exposure to mercury. Environ. Sci. Technol. 2011, 45, 9910-9916. [CrossRef] [PubMed]

23. Nuttall, K.L. Review: Interpreting hair mercury levels in individual patients. Ann. Clin. Lab. Sci. 2006, 36, $248-261$.

24. Sherman, L.S.; Blum, J.D.; Basu, N.; Rajaee, M.; Evers, D.C.; Buck, D.G.; Petrlik, J.; DiGangi, J. Assessment of mercury exposure among small-scale gold miners using mercury stable isotopes. Environ. Res. 2015, 137, 226-234. [CrossRef] [PubMed]

25. Harada, M.; Nakachi, S.; Cheu, T.; Hamada, H.; Ono, Y.; Tsuda, T.; Yanagida, K.; Kizaki, T.; Ohno, H. Monitoring of mercury pollution in Tanzania: Relation between head hair mercury and health. Sci. Total Environ. 1999, 227, 249-256. [CrossRef]

26. Akagi, H.; Malm, O.; Branchesb, F.J.P.; Kinjoa, Y.; Kashima, Y.; Guimaraes, J.; Oliveira, R.; Haraguchi, K.; Pfeiffer, W.; Takizawa, Y.; et al. Human exposure to mercury due to goldmining in the Tapajos River basin, Amazon, Brazil: Speciation of mercury in human hair, blood, and urine. Water Air Soil Pollut. 1995, 80, 85-94. [CrossRef]

27. Ikingura, J.R.; Akagib, H. Monitoring of fish and human exposure to mercury due to gold mining in the Lake Victoria goldfields, Tanzania. Sci. Total Environ. 1996, 9697, 96. [CrossRef]

28. Malm, O.; Branchesb, F.J.P.; Akagi, H.; Castro, M.; Pfeiffer, W.C.; Haradac, M.; Bastosa, W.R.; Katob, H. Mercury and methylmercury in fish and human hair from the Tapajos River Basin, Brazil. Sci. Total Environ. 1995, 175, 141-150. [CrossRef]

29. Calao-Ramos, C.; Bravo, A.G.; Paternina-Uribe, R.; Marrugo-Negrete, J.; Díez, S. Occupational human exposure to mercury in artisanal small-scale gold mining communities of Colombia. Environ. Int. 2021, 146, 106216. [CrossRef] [PubMed]

30. Gao, Y.; De Galan, S.; De Brauwere, A.; Baeyens, W.; Leermakers, M. Mercury speciation in hair by headspace injection-gas chromatography-atomic fluorescence spectrometry (methylmercury) and combustion-atomic absorption spectrometry (Total Hg). Talanta 2010, 82, 1919-1923. [CrossRef] [PubMed]

31. Kehrig, A.; Malm, O.; Akagi, H.; Guimara, J.R.D.; Torres, P.M. Methylmercury in Fish and Hair Samples from the Balbina Reservoir, Brazilian Amazon. Environ. Res. 1998, 77, 84-90. [CrossRef]

32. Dermelj, M.; Horvat, M.; Byrne, A.R.; Stegnar, P. Mercury, methyl-mercury, and selenium in scalp hair of inhabitants from Mediterranean areas. Chemosphere 1987, 16, 877-886. [CrossRef]

33. Al-Majed, N.B.; Preston, M.R. Factors influencing the total mercury and methyl mercury in the hair of the fishermen of Kuwait. Environ. Pollut. 2000, 109, 239-250. [CrossRef] 
34. Díez, S.; Delgado, S.; Aguilera, I.; Astray, J.; Pérez-Gómez, B.; Torrent, M.; Sunyer, J.; Bayona, J.M. Prenatal and early childhood exposure to mercury and methylmercury in Spain, a high-fish-consumer country. Arch. Environ. Contam. Toxicol. 2009, 56, 615-622. [CrossRef]

35. Lebel, J.; Mergler, D.; Branches, F.; Lucotte, M.; Amorim, M.; Larribe, F.; Dolbec, J. Neurotoxic effects of low-level methylmercury contamination in the Amazonian Basin. Environ. Res. 1998, 79, 20-32. [CrossRef] [PubMed]

36. Soria, M.L.; Sanz, P.; Martínez, D.; López-Artíguez, M.; Garrido, R.; Grilo, A.; Repetto, M. Total mercury and methylmercury in hair, maternal and umbilical blood, and placenta from women in the Seville Area. Bull. Environ. Contam. Toxicol. 1992, 48, 494-501. [CrossRef] [PubMed]

37. Akagi, H.; Malm, O.; Kinjo, Y.; Harada, M.; Branches, F.J.P.; Pfeiffer, W.C.; Kato, H. Methylmercury pollution in the Amazon, Brazil. Sci. Total Environ. 1995, 175, 85-95. [CrossRef]

38. Sakamoto, M.; Feng, X.; Li, P.; Qiu, G.; Jiang, H.; Yoshida, M.; Iwata, T.; Liu, X.J.; Murata, K. High exposure of Chinese mercury mine workers to elemental mercury vapor and increased methylmercury levels in their hair. Environ. Health Prev. Med. 2007, 12, 66-70. [CrossRef] [PubMed]

39. Queipo Abad, S.; Rodríguez-González, P.; García Alonso, J.I. Evidence of the direct adsorption of mercury in human hair during occupational exposure to mercury vapour. J. Trace Elem. Med. Biol. 2016, 36, 16-21. [CrossRef] [PubMed]

40. Yasutake, A.; Hachiya, N. Accumulation of inorganic mercury in hair of rats exposed to methylmercury or mercuric chloride. Tohoku J. Exp. Med. 2006, 210, 301-306. [CrossRef] [PubMed]

41. Berglund, M.; Lind, B.; Björnberg, K.A.; Palm, B.; Einarsson, Ö.; Vahter, M. Inter-individual variations of human mercury exposure biomarkers: A cross-sectional assessment. Environ. Health 2005, 11, 20. [CrossRef]

42. Zareba, G.; Cernichiari, E.; Hojo, R.; Nitt, S.M.; Weiss, B.; Mumtaz, M.M.; Jones, D.E.; Clarkson, T.W. Validity of methyl mercury hair analysis: Mercury monitoring in human scalp/nude mouse model. J. Appl. Toxicol. 2007, 27, 511-518. [CrossRef] [PubMed]

43. UN Environment Programme. Technical Background Report to the Global Mercury Assessment 2018; Arctic Monitoring and Assessment Programme: Oslo, Norway/UN Environment Programme, Chemicals and Health Branch: Geneva, Switzerland, 2019.

44. Moody, K.H.; Hasan, K.M.; Aljic, S.; Blakeman, V.M.; Hicks, L.P.; Loving, D.C.; Moore, M.E.; Hammett, B.S.; Silva-González, M.; Seney, C.S.; et al. Mercury emissions from Peruvian gold shops: Potential ramifications for Minamata compliance in artisanal and small-scale gold mining communities. Environ. Res. 2020, 182, 109042. [CrossRef]

45. Diringer, S.; Feingold, B.J.; Ortiz, E.J.; Gallis, J.A.; Arauo-Flores, J.M.; Berky, A.; Pan, W.K.Y.; Hsu-kim, H. River transport of mercury from artisanal and small-scale gold mining and risks for dietary mercury exposure in Madre de Dios, Peru †. Environ. Sci. Process. Impacts 2015, 17, 478-487. [CrossRef]

46. Diringer, S.E.; Berky, A.J.; Marani, M.; Ortiz, E.J.; Karatum, O.; Plata, D.L.; Pan, W.K.; Hsu-Kim, H. Deforestation due to artisanal and small-scale gold mining exacerbates soil and mercury mobilization in Madre de Dios, Peru. Environ. Sci. Technol. 2020, 54, 286. [CrossRef]

47. Asner, G.P.; Tupayachi, R. Accelerated losses of protected forests from gold mining in the Peruvian Amazon. Environ. Res. Lett. 2017, 12, 094004. [CrossRef]

48. Asner, G.P.; Llactayo, W.; Tupayachi, R.; Ráez, E. Elevated rates of gold mining in the amazon revealed through high-resolution monitoring. Proc. Natl. Acad. Sci. USA 2013, 110, 18454-18459. [CrossRef] [PubMed]

49. Swenson, J.J.; Carter, C.E.; Domec, J.C.; Delgado, C.I. Gold mining in the Peruvian Amazon: Global prices, deforestation, and mercury imports. PLoS ONE 2011, 6, e18875. [CrossRef] [PubMed]

50. Martinez, G.; McCord, S.A.; Driscoll, C.T.; Todorova, S.; Wu, S.; Araújo, J.F.; Vega, C.M.; Fernandez, L.E. Mercury contamination in riverine sediments and fish associated with artisanal and small-scale gold mining in Madre de Dios, Peru. Int. J. Environ. Res. Public Health 2018, 15, 1584. [CrossRef] [PubMed]

51. Moreno-Brush, M.; Rydberg, J.; Gamboa, N.; Storch, I.; Biester, H. Is mercury from small-scale gold mining prevalent in the southeastern Peruvian amazon? Environ. Pollut. 2016, 218, 150-159. [CrossRef] [PubMed]

52. Weinhouse, C.; Ortiz, E.J.; Berky, A.J.; Bullins, P.; Hare-grogg, J.; Morales, A.; Hsu-kim, H.; Pan, W.K. Hair mercury level is associated with anemia and micronutrient status in children living near artisanal and small-scale gold mining in the Peruvian Amazon. Am. J. Trop. Med. Hyg. 2018, 97, 1886-1897. [CrossRef] [PubMed]

53. Weinhouse, C.; Gallis, J.A.; Ortiz, E.; Berky, A.J.; Morales, A.M.; Diringer, S.E.; Harrington, J.; Bullins, P.; Rogers, L.; Hare, J.; et al. A population-based mercury exposure assessment near an artisanal and small scale gold mining site in the Peruvian Amazon. JESEE 2019, 31, 126-136. [CrossRef]

54. Ashe, K. Elevated mercury concentrations in humans of Madre de Dios, Peru. PLoS ONE 2012, 7, e33305. [CrossRef] [PubMed]

55. Yard, E.E.; Horton, J.; Schier, J.G.; Caldwell, K.; Sanchez, C.; Lewis, L.; Gastaňaga, C. Mercury exposure among artisanal gold miners in Madre de Dios, Peru: A cross-sectional study. J. Med. Toxicol. 2012, 8, 441-448. [CrossRef]

56. Gonzalez, D.J.X.; Arain, A.; Fernandez, L.E. Mercury exposure, risk factors, and perceptions among women of childbearing age in an artisanal gold mining region of the Peruvian Amazon. Environ. Res. 2019, 179, 108786. [CrossRef]

57. Reuben, A.; Frischtak, H.; Berky, A.; Ortiz, E.J.; Morales, A.M.; Hsu-Kim, H.; Pendergast, L.; Pan, W.K. Elevated Hair Mercury Levels Are Associated with Neurodevelopmental Deficits in Children Living near Artisanal and Small-Scale Gold Mining in Peru. GeoHealth 2020, 4, e2019GH000222. [CrossRef] [PubMed]

58. Veiga, M.M.; Baker, R.F. Protocols for Environmental and Health Assessment of Mercury Released by Artisanal and Small-Scale Gold Miners; Global Mercury Project: Vienna, Austria, 2004. 
59. World Health Organization. Assessment of Prenatal Exposure to Mercury: Standard Operating Procedures; WHO Regional Office for Europe: Copenhagen, Denmark, 2018.

60. Drasch, G.; Reilly, S.B.; Beinhoff, C.; Roider, G.; Maydl, S. The Mt. Diwata study on the philippines 1999-Assessing mercury intoxication of the population by small scale gold mining. Sci. Total Environ. 2001, 267, 151-168. [CrossRef]

61. Morton, J.; Carolan, V.A.; Gardiner, P.H.E. Removal of exogenously bound elements from human hair by various washing procedures and determination by inductively coupled plasma mass spectrometry. Anal. Chim. Acta 2002, 455, 23-34. [CrossRef]

62. Li, Y.F.; Chen, C.; Li, B.; Wang, J.; Gao, Y.; Zhao, Y.; Chai, Z. Scalp hair as a biomarker in environmental and occupational mercury exposed populations: Suitable or not? Environ. Res. 2008, 107, 39-44. [CrossRef] [PubMed]

63. Esteban, M.; Schindler, B.K.; Jiménez, J.A.; Koch, H.M.; Angerer, J.; Rosado, M.; Gómez, S.; Casteleyn, L.; KolossaGehring, M.; Becker, K.; et al. Mercury analysis in hair: Comparability and quality assessment within the transnational COPHES/DEMOCOPHES project. Environ. Res. 2015, 141, 24-30. [CrossRef]

64. Barbosa, A.C.; Jardim, W.; Dórea, J.G.; Fosberg, B.; Souza, J. Hair mercury speciation as a function of gender, age, and body mass index in inhabitants of the Negro River Basin, Amazon, Brazil. Arch. Environ. Contam. Toxicol. 2001, 40, 439-444. [CrossRef]

65. Basu, N.; Clarke, E.; Green, A.; Calys-Tagoe, B.; Chan, L.; Dzodzomenyo, M.; Fobil, J.; Long, R.N.; Neitzel, R.L.; Obiri, S.; et al. Integrated assessment of artisanal and small-scale gold mining in Ghana-part 1: Human health review. Int. J. Environ. Res. Public Health 2015, 12, 5143-5176. [CrossRef] [PubMed]

66. Hinton, J.J.; Veiga, M.M.; Veiga, A. Clean artisanal gold mining: A utopian approach? J. Clean. Prod. 2003, 11, 99-115. [CrossRef]

67. Fraser, B. Peruvian gold rush threatens health and the environment. Environ. Sci. Technol. 2009, 43, 7162-7164. [CrossRef]

68. Marinho, J.S.; Lima, M.O.; De Oliveira Santos, E.C.; De Jesus, I.M.; Pinheiro, M.D.C.N.; Alves, C.N.; Muller, R.C.S. Mercury speciation in hair of children in three communities of the Amazon, Brazil. BioMed Res. Int. 2014, 2014, 945963. [CrossRef]

69. Basu, N.; Horvat, M.; Evers, D.C.; Zastenskaya, I.; Weihe, P.; Tempowski, J. A state-of-the-science review of mercury biomarkers in human populations worldwide between 2000 and 2018. Environ. Health Perspect. 2018, 126, 106001. [CrossRef] [PubMed]

70. Park, J.D.; Zheng, W. Human exposure and health effects of inorganic and elemental mercury. J. Prev. Med. Public Health 2012, 45, 344-352. [CrossRef] [PubMed]

71. Hopps, H. The biologic bases for using hair and nail for analyses of trace elements. Sci. Total Environ. 1977, 7, 71-89. [CrossRef]

72. UN Environment Programme. Minamata Convention on Mercury; Cambridge University Press: Cambridge, UK, 2017. [CrossRef]

73. Congreso de la República del Perú. Ley Para Fortalecer La Prevención, Mitigación y Atención de La Salud Afectada Por La Contaminación Con Metales Pesados y Otras. El Peurano 2021, 16001, 3. 